\title{
Effect of Brain CYP2B Inhibition on Brain Nicotine Levels and Nicotine Self-Administration
}

\author{
Kristine LP Garcia ${ }^{1,2,3}$, Kathy Coen ${ }^{3}$, Sharon Miksys ${ }^{1,2,3}$, Anh Dzung Lê ${ }^{1,2,3}$ and Rachel F Tyndale \\ 'Department of Pharmacology and Toxicology, University of Toronto, Toronto, Ontario, Canada; ${ }^{2}$ Department of Psychiatry, University of Toronto, \\ Toronto, Ontario, Canada; ${ }^{3}$ Campbell Family Mental Health Research Institute, Centre for Addiction and Mental Health, Toronto, Ontario, Canada
}

\begin{abstract}
The CYP2B enzyme is expressed in human and rat brain, and metabolizes many CNS-acting drugs. The gene that encodes human CYP2B6 is highly polymorphic, where the variation in brain enzyme levels could result in altered brain drug levels. CYP2B can metabolize nicotine, the main psychoactive ingredient in cigarettes; if altered brain CYP2B activity can influence nicotine brain levels, it could influence nicotinemediated behaviors. To investigate this, a mechanism-based inhibitor selective for CYP2B, C8-xanthate (20 $\mu$ g), was administered intracerebroventricularly (ICV) into the brain of rats, and $22 \mathrm{~h}$ later, nicotine levels were measured by in vivo microdialysis following nicotine ( $150 \mu \mathrm{g} / \mathrm{kg}$ intravenous). Brain nicotine levels from 15 to $30 \mathrm{~min}$ and the $A \cup C_{0-45 m i n}$ were both twofold higher $(p<0.05)$ with C8-xanthate vs vehicle pretreatment; there was no difference in peripheral nicotine levels. Rats were then given ICV pretreatment with C8-xanthate/ASCF and underwent intravenous nicotine self-administration with $3.75-30 \mu g / k g$ per infusion dose. C8-xanthate pretreatment increased responding in progressive ratio $(15 \mu \mathrm{g} / \mathrm{kg}$ per infusion dose, $p<0.05)$. In a separate cohort, C8-xanthate increased the percentage of rats that acquired self-administration $(7.5 \mu \mathrm{g} / \mathrm{kg}$ per infusion dose, $p<0.05)$ from $40 \%$ after vehicle pretreatment to 100\%, with no difference in peripheral nicotine levels measured at the end of behavior. In a third cohort, C8-xanthate increased the number of sessions required to meet extinction criteria $(p<0.05)$. Together these data demonstrate that the brain CYP2B activity can influence nicotine brain levels and subsequent behaviors independent of hepatic metabolism. This suggests that human smokers with variable CYP2B brain levels could have different nicotine levels and reinforcement, which might have a role in smoking behaviors and dependence.

Neuropsychopharmacology (2015) 40, 1910-19I8; doi:I0.1038/npp.2015.40; published online II March 20I5
\end{abstract}

\section{INTRODUCTION}

There is increasing evidence to support that extra-hepatic expression of cytochrome P450 (CYP) enzymes, which are involved in the metabolism of numerous clinical drugs, can influence local drug levels and response (Ferguson and Tyndale, 2011). The CYP isoform CYP2B is expressed in various regions of the brain in humans (Gervot et al, 1999; Miksys et al, 2003), monkeys (Lee et al, 2006), and rats (Miksys et al, 2000). Brain CYP2B is active and is able to metabolize its substrates in situ (Miksys and Tyndale, 2009), and many CYP2B substrates act within the central nervous system (CNS), such as bupropion (Hesse et al, 2000), methadone (Gerber et al, 2004), propofol (Ekins et al, 2008), and nicotine (Yamanaka et al, 2005; Yamazaki et al, 1999). Therefore, CYP2B in the brain may contribute to local metabolism of its CNS-acting substrates and to resulting drug response.

* Correspondence: Dr RF Tyndale, Department of Pharmacology and Toxicology, University of Toronto, I King's College Circle, Medical Sciences Building, Toronto, Ontario M5S IA8, Canada, Tel: + | 416978 6374, Fax: + 416 978-6395, E-mail: r.tyndale@utoronto.ca Received 27 October 2014; revised 13 January 2015; accepted 2 February 20I5; accepted article preview online 5 February 2015
CYP2B expression is influenced by both genetic and environmental factors. The human CYP2B6 gene is highly polymorphic (Zanger et al, 2007), and genetic variation in the liver expression of this enzyme can influence the systemic levels of its substrates (Crettol et al, 2005; Dobrinas et al, 2013; Kirchheiner et al, 2003; Tsuchiya et al, 2004). One variant of $C Y P 2 B 6, C Y P 2 B 6^{*} 6$, results in a reduction of CYP2B protein levels (Lang et al, 2001); this protein reduction is also found in the brains of individuals with a CYP2B6*6 allele (Miksys et al, 2003). CYP2B expression can also be altered by environmental factors, for example, phenobarbital can induce CYP2B expression in both the liver and brain of rats (Anandatheerthavarada et al, 1992; Schilter and Omiecinski, 1993) and monkeys (Lee et al, 2006). Thus, variation in brain CYP2B activity may alter the levels of a substrate locally, possibly altering the resulting drug response. We have previously shown that the selective inhibition of CYP2B activity in the brain by central administration of the mechanism-based inhibitor C8xanthate (C8X), which is selective for CYP2B (Yanev et al, 1999), can modify the brain levels and subsequent behavioral response of the CYP2B substrates propofol (Khokhar and Tyndale, 2011) and chlorpyrifos (Khokhar and Tyndale, 2012, 2014). These studies first established that altering the 
brain CYP2B activity can affect the pharmacological and the toxicological response to CNS-acting compounds.

Nicotine, the main psychoactive ingredient in cigarettes, can be metabolized by CYP2B in humans (Yamanaka et al, 2005) and in rats (Hammond et al, 1991). Nicotine enters the brain from the periphery where it is thought to exert its reinforcing effect by acting on the brain reward center nicotinic acetylcholine receptors that release dopamine (Di Chiara and Imperato, 1988; Marshall et al, 1997; Rapier et al, 1988). In vitro rat brain membranes are capable of metabolizing nicotine to cotinine (Jacob et al, 1997); however, it is unknown whether altering the brain CYP2B activity can significantly influence nicotine brain levels in vivo following peripheral administration. To address this question, nicotine brain levels produced by the IV administration of nicotine were measured via in vivo microdialysis following intracerebral ventricular (ICV) injection of C8X.

If reducing brain CYP2B activity can increase nicotine brain levels, is this increase sufficient to alter the behavioral response to nicotine? People with the $C Y P 2 B 6^{*} 6$ variant are more likely to become smokers (Hoffmann et al, 2006) and to relapse during cessation compared with normal metabolizers (Lee et al, 2007a; Lerman et al, 2007); however, this variant has no effect on peripheral plasma nicotine levels (Lee et al, 2007b), suggesting that the observed differences in acquisition and cessation may be due to genetic variation in brain CYP2B6 levels and resulting higher brain nicotine levels. To examine whether inhibiting brain CYP2B could alter nicotine self-administration (NSA) behavior (Corrigall and Coen, 1989; Donny et al, 1999), rats were given C8X ICV before or during NSA; if inhibition of brain CYP2B increases nicotine levels in brain, then a left shift in the dose-response curve would be anticipated. The effect of brain CYP2B inhibition was first tested on the motivation to obtain nicotine through the progressive-ratio (PR) schedule. On the basis of these findings, we examined the impact of brain CYP2B inhibition on acquisition of NSA, extinction, and reinstatement of nicotine-seeking behavior. In both microdialysis and behavioral studies, peripheral nicotine levels were assessed to confirm that central injections of CYP2B inhibitors had no effect on peripheral nicotine or cotinine levels.

\section{MATERIALS AND METHODS}

Adult male Wistar rats (250-300 g, Charles River Laboratories, Quebec, Canada) were housed singly on a 12-h light/ dark cycle, and water was provided ad libitum. Stainless-steel guide cannulae were implanted into the right lateral ventricle for ICV injection and for the insertion of microdialysis probes (anterior-posterior $0.9 \mathrm{~mm}$, lateral $1.4 \mathrm{~mm}$, and dorsoventral $2.6 \mathrm{~mm}$ (microdialysis) or $3.6 \mathrm{~mm}$ (ICV injection), from Bregma (Paxinos and Watson, 1986)). For brain CYP2B inhibition, C8-xanthate (C8X, Toronto Research Chemicals, Toronto, ON, Canada), a CYP2B-specific inhibitor (Yanev et al, 2000), was injected ICV, $20 \mu \mathrm{g}$ in $4 \mu \mathrm{l}$ of artificial cerebrospinal fluid (ACSF) over $1 \mathrm{~min}$; the injector was removed after $1 \mathrm{~min}$. This C8X dose was previously optimized for brain, but not liver, CYP2B inhibition (Khokhar and Tyndale, 2011, 2012, 2014) and retested here with nicotine as a substrate. Sterile nicotine solution
(Sigma-Aldrich, Oakville, ON, Canada) was prepared daily as concentration of base in saline, $\mathrm{pH}$ 6.8-7.2.

\section{In Vivo Nicotine Microdialysis}

Microdialysis experiments were carried out in the light phase. Twenty-two hours before microdialysis, rats were given a single ICV injection of ACSF vehicle $(n=10)$ or C8X $(n=9)$ (Figure 1a). To provide an estimate of the increase in nicotine dialysate levels due to brain CYP2B inhibition (ICV $\mathrm{C} 8 \mathrm{X}$ ) in terms of peripheral nicotine dosing, a dose-response curve for nicotine dialysate levels was generated with a separate cohort of animals (No ICV Tx, $n=5$ per nicotine dose). Ringer's solution ( $147 \mathrm{mM} \mathrm{Na}^{+}, 2 \mathrm{mM} \mathrm{Ca}^{2+}, 4 \mathrm{mM} \mathrm{K}^{+}$, $155 \mathrm{mM} \mathrm{Cl}^{-}, \mathrm{pH}$ 6.0) was perfused through concentric silicacoated probes with $2 \mathrm{~mm}$ membranes (MD-2200; Bioanalytical Systems, West Lafayette, IN) by an infusion pump at $2 \mu \mathrm{l} / \mathrm{min}$. Baseline dialysate was collected for $15 \mathrm{~min}$ before IV nicotine injection (into the tail vein, $150 \mu \mathrm{g} / \mathrm{kg}$ for ACSF and C8X groups, and 150, 225, and $300 \mu \mathrm{g} / \mathrm{kg}$ for No ICV Tx groups in saline, $\mathrm{pH}$ 6.8-7.2), after which the dialysate was collected on ice in 15-min bins for $2 \mathrm{~h}$ and $15 \mathrm{~min}$. Blood (200-300 $\mu \mathrm{l})$ was collected from the saphenous vein at 15 and 75 min postinjection. For nicotine and cotinine quantification, $30 \mu \mathrm{l}$ of dialysate was diluted to $100 \mu \mathrm{l}$ with deuteriumlabeled internal nicotine and cotinine standards $(20 \mathrm{ng} / \mathrm{ml}$ in $0.01 \mathrm{M} \mathrm{HCl}$ ), while $100 \mu \mathrm{l}$ plasma samples were prepared as previously described (Craig et al, 2014; Vieira-Brock et al, 2011); dialystate and extracted plasma were then analyzed by liquid chromatography-mass spectrometry (LC-MS) (Craig et al, 2014).

\section{Nicotine Self-Administration}

Seven days after ICV cannula implant, catheters were implanted into the right jugular vein as previously described (Garcia et al, 2014; Shram et al, 2008). To maintain patency, catheters were flushed daily with sterile heparin in saline $(0.1 \mathrm{ml}, 50 \mathrm{U} / \mathrm{ml})$. Thiopental $(2-4 \mathrm{mg}, \mathrm{IV}, 20 \mathrm{mg} / \mathrm{ml})$ was used to test catheter patency after testing, and nonpatent animal data were removed from analysis. NSA was carried out in 16 operant chambers operated by a computer-controlled interface system (Med Associates, St Albans, VT) under previously described conditions (Garcia et al, 2014).

\section{Progressive-Ratio Schedule}

Before surgery, rats were food trained to learn the selfadministration operant behavior as previously described (Garcia et al, 2014). Following recovery from IV surgery, rats $(n=12$ per dose) underwent daily 1 -h NSA sessions under FR1 and FR2 for 5 days at a single nicotine dose of 7.5, 15, or $30 \mu \mathrm{g} / \mathrm{kg}$ (Figure $1 \mathrm{~b}$ ). Rats then underwent a PR schedule of reinforcement at their same training dose, in 2-h daily sessions for five sessions to create a baseline of responding, as previously described (Garcia et al, 2014). At $22 \mathrm{~h}$ before the sixth PR session, all animals received one ICV injection of ACSF, then underwent three PR sessions (sessions 6, 7, and 8). At $22 \mathrm{~h}$ before the ninth PR session, all animals received one ICV injection of $C 8 X$, then underwent three PR sessions $(9,10$, and 11$)$. 
a In vivo nicotine microdialysis

b

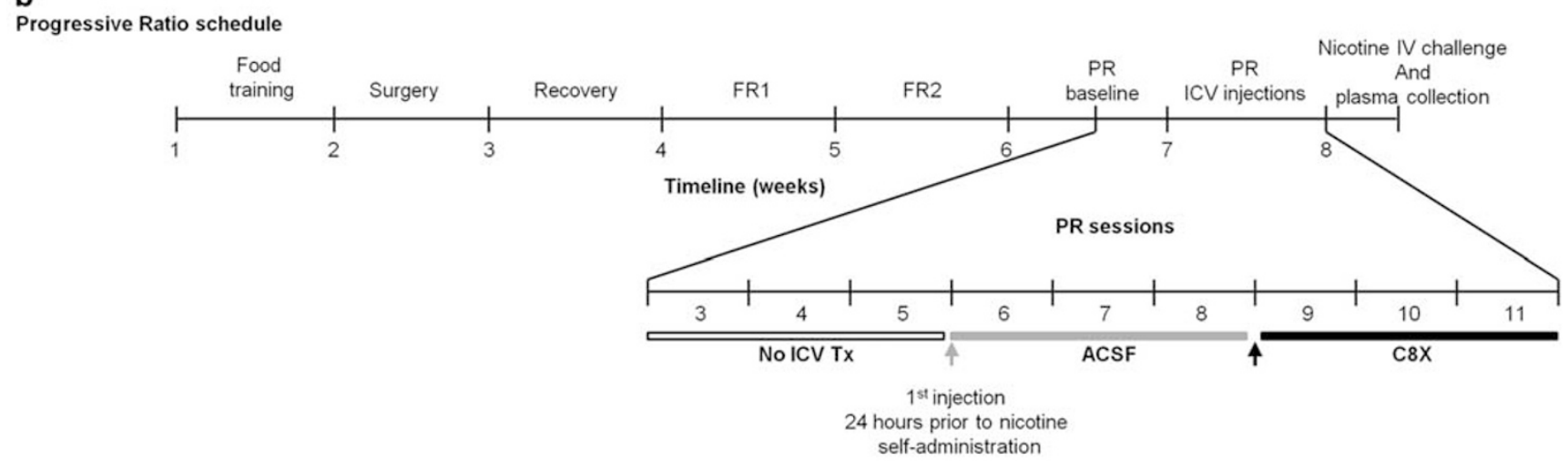

C

Acquisition, extinction and reinstatement

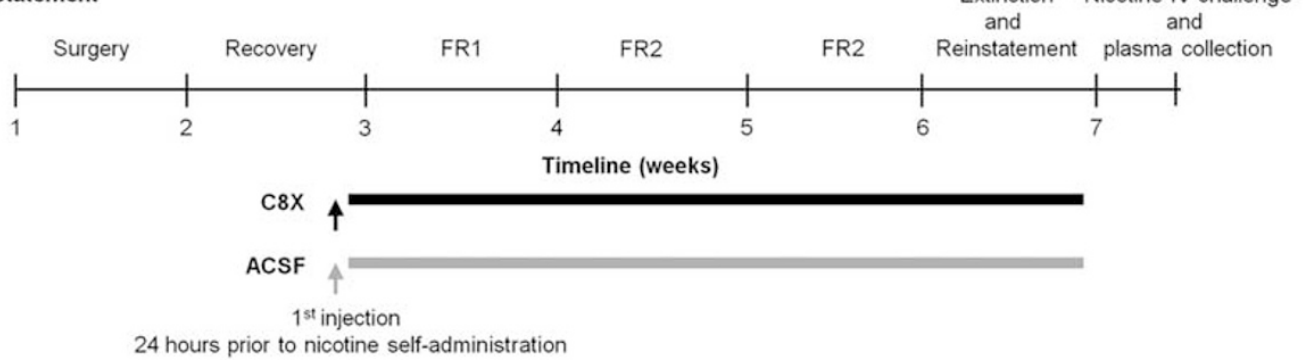

Figure I Experimental study design and timelines for (a) rats that underwent in vivo nicotine microdialysis, (b) rats that underwent the progressive-ratio (PR) schedule of reinforcement where they received a single ICV injection of ACSF and then C8X in a within-animal design, and (c) rats that underwent acquisition, maintenance, extinction, and nicotine reinstatement experiments under a fixed-ratio (FR) schedule of reinforcement where they received daily ICV injections of ACSF or C8X.

After PR testing, rats received one ICV injection of ACSF or C8X, $24 \mathrm{~h}$ before a bolus injection of nicotine $(200 \mu \mathrm{g} / \mathrm{kg} /$ IV). Blood was collected from the saphenous vein at 15 and 60 min post-nicotine injection, and trunk blood was collected at $120 \mathrm{~min}$. Plasma was analyzed for nicotine and cotinine by high-performance liquid chromatography (Siu et al, 2006).

\section{Acquisition, Extinction, and Reinstatement}

Rats were assigned to receive either C8X or ACSF $(n=12$ per dose) ICV injections daily, $22 \mathrm{~h}$ before each behavior session. Seven days after IV surgery, animals underwent NSA without food training (Figure 1c) at three infusion doses $(3.75,7.5$, or $15 \mu \mathrm{g} / \mathrm{kg})$ that were found previously to fall along the ascending limb of nicotine's dose-response curve for spontaneous acquisition (Garcia et al, 2014). Rats underwent 2-h daily NSA sessions under a FR1 schedule for 5 days and then a FR2 schedule for another 5 days, which was used to determine acquisition (Garcia et al, 2014; Shram et al, 2008).
Another cohort of rats $(n=24$ each for C8X and ACSF groups) trained with $7.50 \mu \mathrm{g} / \mathrm{kg}$ nicotine underwent extinction and reinstatement. Following acquisition, where rats were trained to self-administer nicotine and given daily ICV injections as described above, rats continued NSA under the FR2 schedule for 3 extra days and then underwent four 2-h extinction sessions (one per day) during which responding on the active lever had no consequences. The effects of CYP2B inhibition on reinstatement of nicotine seeking were then evaluated. On reinstatement test day, rats were subjected to multiple 1-h extinction sessions until they met extinction criteria $(<10$ active lever presses in two consecutive sessions). They were then given saline IV $(0.1 \mathrm{ml} / \mathrm{kg})$ $5 \mathrm{~min}$ before one 1-h session. Following the saline session, reinstatement of nicotine seeking induced by different IV priming doses of nicotine $(15,30$, and $60 \mu \mathrm{g} / \mathrm{kg}, 0.1 \mathrm{ml} / \mathrm{kg})$ was evaluated in ascending order over 3 different test days. After 1 week, this extinction and reinstatement cycle was repeated with SC saline and nicotine $(15,30,60$, and $150 \mu \mathrm{g} / \mathrm{kg})$. 
Twenty-four hours after the last ICV injection of C8X or ACSF, rats received four nicotine infusions $(7.50 \mu \mathrm{g} / \mathrm{kg}$, one per min) in the operant chambers. Trunk blood was collected either 1 or $5 \mathrm{~min}$ after the last (fourth) infusion and analyzed by LC-MS for nicotine and cotinine as described above.

\section{Statistical Analysis}

Nicotine dialysate levels and AUCs after C8X and ACSF treatment were analyzed by Student's $t$-test. Plasma nicotine dose response was analyzed using a one-way ANOVA. The log-transformation of final completed ratios in $\mathrm{PR}$, and active and inactive lever presses and reinforcements in FR were analyzed with repeated-measures ANOVA. Post-hoc analyses for all ANOVAs were conducted using Bonferroni tests. NSA acquisition data were analyzed using a Fisher's Exact test (two sided). Extinction sessions were analyzed using Kaplan-Meier survival analysis followed by a log-rank test. Significance level for all comparisons was $p=0.05$.

\section{RESULTS}

\section{ICV Injection of C8X Increases Circulating Nicotine Levels in the Rat Brain}

Brain levels of nicotine in dialysate collected at 15-min intervals following IV infusion of $150 \mu \mathrm{g} / \mathrm{kg}$ of nicotine in C8X- and ACSF-treated rats are shown in Figure 2a. Mean nicotine dialysate levels were higher with C8X treatment over the first 45 min compared with ACSF treatment, resulting in significant differences at the time of maximum nicotine concentration (collected from 15 to $30 \mathrm{~min}$ post-nicotine; $t(17)=-2.27, p=0.03$ ) (Figure $2 \mathrm{a})$ and for $\mathrm{AUC}_{0-45}(t(17)=$ $2.23, p=0.04$ ) (Figure 2b). Mean AUC $_{45-135}$ was not different $(p=0.79)$ between ICV treatments (Figure 2b). Plasma levels of nicotine and its major metabolite cotinine, obtained during microdialysis, were not significantly different between C8X and ACSF, confirming that ICV injection of inhibitor did not alter peripheral nicotine metabolism (Figure 2c).

Nicotine dialysate levels increased with increasing nicotine dose, demonstrating that the microdialysis method was capable of detecting higher levels of nicotine (Figure 2d, shown for 15-30 min post-nicotine) consistent with the increasing plasma levels of nicotine observed (Figure 2e, shown for 15 and $75 \mathrm{~min}$ post-nicotine). Nicotine dialysate levels after ICV ACSF treatment were similar to nicotine levels without ICV pretreatment (No ICV Tx), as expected, whereas nicotine levels after C8X treatment were higher than both control groups (tested at $150 \mu \mathrm{g} / \mathrm{kg}$ ) corresponding to a $25 \%$ increase in the apparent dose of nicotine. Plasma nicotine levels in animals pretreated ICV with ACSF and C8X were similar to the levels measured in No ICV animals $(150 \mu \mathrm{g} / \mathrm{kg}$, Figure 2e). Together, this indicates that ICV injections of C8X can increase nicotine levels in the brain, while leaving the systemic levels unchanged.

\section{ICV Injection of C8X Increases Final Ratios Completed under a PR Schedule}

To test whether single ICV C8X injections could alter NSA behavior, the effect of $\mathrm{C} 8 \mathrm{X}$ on $\mathrm{PR}$ breakpoint (final ratio of responding completed) was examined. Rats that acquired NSA and underwent five PR baseline sessions were then treated with ACSF ICV and tested under PR. There was no difference between final ratios completed during baseline PR compared with ACSF treatment indicating little to no effect of ICV injection, or time, on the measure of PR (data not shown). All rats were then given C8X ICV and tested under PR. Mean final ratios completed for rats after C8X treatment were higher than ACSF at all infusion doses (Figure 3a) and repeated measures ANOVA within each dose group revealed that this was significantly different at $15 \mu \mathrm{g} / \mathrm{kg}(\mathrm{F}(1,7)=$ 7.365, $p=0.03$ ).

There was no difference between C8X and ACSF ICV treatment in the plasma nicotine and cotinine collected after an IV bolus injection of nicotine $(200 \mu \mathrm{g} / \mathrm{kg}$ ) (Figure $3 \mathrm{~b}$ and c). This indicated that central injections of C8X were not inhibiting the hepatic CYP2B and the peripheral nicotine metabolism.

\section{ICV Injection of C8X Shifts Nicotine's Dose-Response Curve for Acquisition of NSA}

Training-naive rats given daily pretreatment ACSF ICV injections showed an ascending dose-response curve for the proportion of animals that acquired NSA between 3.75 and $15 \mu \mathrm{g} / \mathrm{kg}$ infusion doses (Figure 4 ). Around $40 \%$ of the rats that self-administered 3.75 and $7.5 \mu \mathrm{g} / \mathrm{kg}$ of nicotine acquired NSA, whereas almost all rats (86\%) that self-administered $15 \mu \mathrm{g} / \mathrm{kg}$ met acquisition criteria. Rats given C8X ICV injections also showed dose-dependent acquisition under the same infusion doses where $\sim 20 \%$ of rats acquired NSA at the lowest dose tested; however, at 7.5 and $15 \mu \mathrm{g} / \mathrm{kg}$, essentially all animals acquired NSA (Figure 4) resulting in a significant difference between ICV treatments at the $7.5 \mu \mathrm{g} /$ $\mathrm{kg}$ acquisition dose $(p<0.001$, Fisher's exact). This apparent leftward shift in nicotine's dose-response acquisition curve with C8X ICV is consistent with the higher levels of nicotine observed with C8X ICV during microdialysis (Figure 2a).

There was no difference in active and inactive lever presses by session during FR1 and FR2 between C8X- and ACSFtreated rats trained at $7.5 \mu \mathrm{g} / \mathrm{kg}$. Mean active lever \pm SEM was $40 \pm 15$ (ACSF) vs $83 \pm 23$ (C8X) in FR1 and $101 \pm 24$ (ACSF) vs $122 \pm 24(\mathrm{C} 8 \mathrm{X})$ in FR2, and mean inactive lever \pm SEM was $11 \pm 8$ (ACSF) vs $25 \pm 6(\mathrm{C} 8 \mathrm{X})$ in FR1 and $33 \pm 17$ (ACSF) vs $41 \pm 10$ (C8X) in FR2. In ACSF-treated rats that did not meet acquisition criteria, there was no difference in active $v s$ inactive lever presses (FR1: $14 \pm 6$ vs $10 \pm 6$, FR2: $8 \pm 2$ vs $9 \pm 6)$ and reinforcements dropped from FR1 to FR2 $(14 \pm 7$ to $9 \pm 6)$; all C8X-treated rats met acquisition criteria.

\section{ICV Injection of C8X Increased the Number of Sessions to Extinction but Did Not Influence Reinstatement of Nicotine-Seeking Behavior}

There was no difference in active lever presses during the four extinction sessions between ACSF- and C8X-treated rats (Supplementary Figure). As animals underwent multiple extinction sessions until they met extinction criteria, the number of sessions that animals needed before they met extinction criteria were examined, where C8X-treated animals, on average, required more sessions to meet the criteria compared with ACSF animals (Figure 5a, $p=0.03$ ). 

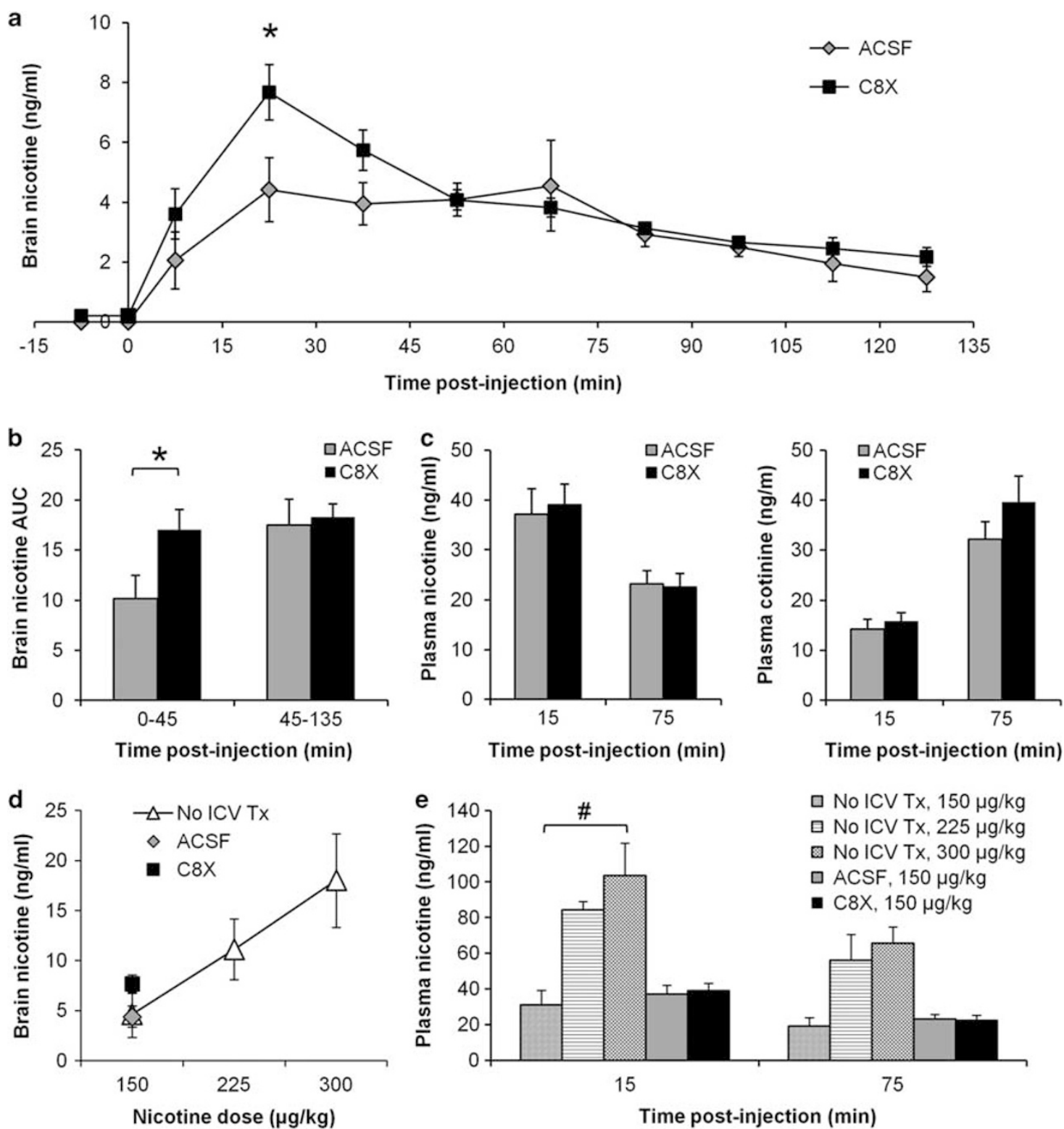

Figure 2 ICV injection of C8X increases circulating nicotine levels in the lateral ventricles measured by in vivo microdialysis. (a) Nicotine dialysate levels were higher after C8X treatment $(n=9)$ compared with ACSF $(n=10) \quad 15-30$ min postinjection $(150 \mu \mathrm{g} / \mathrm{kg} / \mathrm{IV}$, which was the lowest dose of nicotine that produced brain dialysate concentrations of nicotine above the limit of detection for our LC-MS assay (I ng/ml)). (b) Nicotine dialysate AUCs were higher after C8X treatment compared with ACSF from 0 to $45 \mathrm{~min}$. (c) Nicotine and cotinine plasma levels obtained during microdialysis were not different between C8X and ACSF treatment. (d) Nicotine dose-response curve for dialysate collected I5-30 min post-nicotine in No ICV Tx animals ( $n=5$ per dose). Mean nicotine dialysate collected I5-30 min post-nicotine for C8X and ACSF-treated animals are also shown for comparison. (e) Nicotine dose-response curve for plasma levels collected during microdialysis in No ICV Tx animals. Plasma levels increased dose-dependently at I5 min post-nicotine $(F(2, I 2)=|0.4|, p<0.00 I)$. Mean plasma nicotine levels for C8X- and ACSF-treated animals are shown for comparison. Data shown as mean \pm SEM, ${ }^{*} p<0.05$, C8X vs ACSF, ${ }^{\#} p<0.05$, between doses within No ICV Tx.

After extinction, rats were given a single saline injection (IV or SC), and they underwent one session to record responding after an injection of the same volume. There was no difference between active lever presses during extinction and after saline injection (data not shown). After the saline session, animals were tested for reinstatement with increasing IV nicotine priming doses $(15,30$, and $60 \mu \mathrm{g} / \mathrm{kg}$ ). C8X- and ACSF-treated rats did not reinstate their nicotine-seeking behavior at any nicotine priming dose tested: active lever presses after a saline injection $v s$ all nicotine priming doses were not significantly different for both groups (Figure $5 \mathrm{~b}$ ). When active lever presses between C8X and ACSF groups were compared, there was no significant difference at any nicotine priming dose tested. After reinstatement, animals returned to extinction and were tested with SC nicotine priming doses $(15,30,60$, and $150 \mu \mathrm{g} / \mathrm{kg}$ ). Within treatment, there was a significant effect of dose on active lever presses for $\mathrm{C} 8 \mathrm{X}(\mathrm{F}(4,88)=22.403$, 

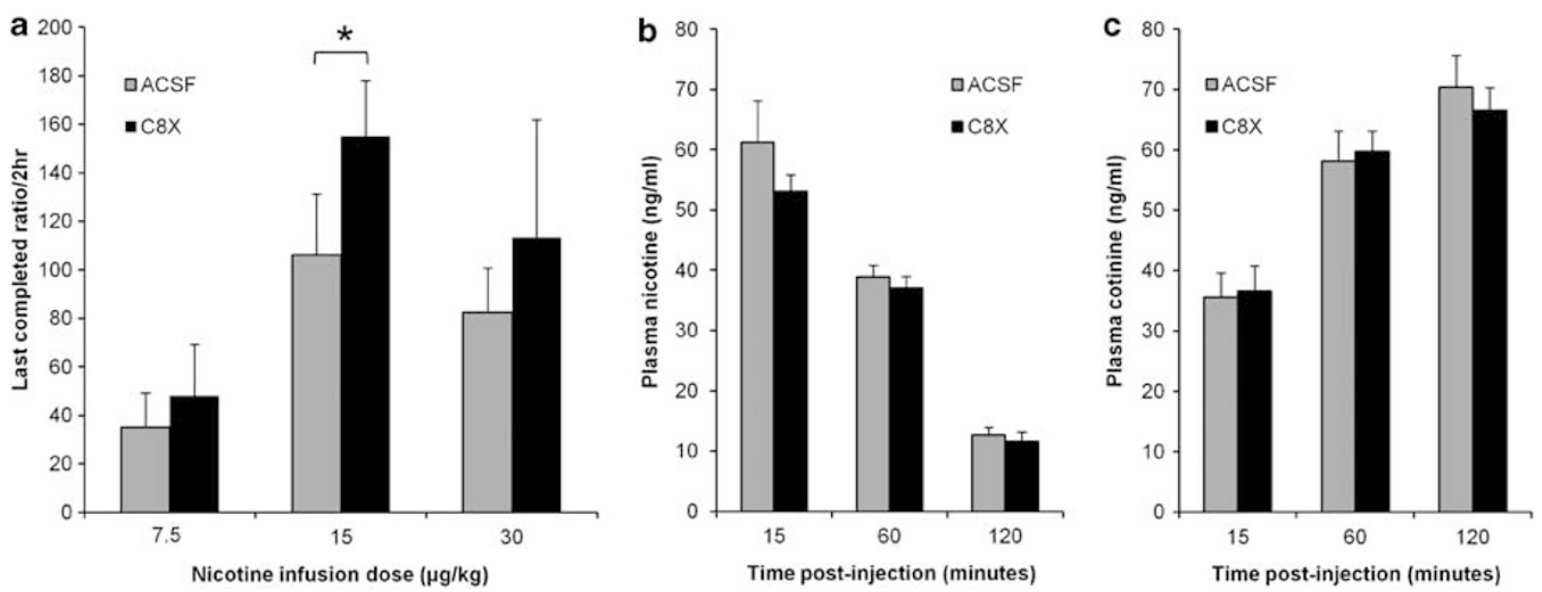

Figure $3 \mathrm{ICV}$ injection of C8X can increase motivation to obtain nicotine in the PR without altering peripheral nicotine metabolism. (a) C8X increased final ratios completed during PR compared with ACSF for animals trained at $7.5 \mu \mathrm{g} / \mathrm{kg}(n=8), 15 \mu \mathrm{g} / \mathrm{kg}(n=8)$, and $30 \mu \mathrm{g} / \mathrm{kg}(n=7)$. Mean final ratio completed was calculated using the mean log transformed final ratio from the three sessions following ICV injection of ACSF or C8X, *P $<0.05$, C8X vs ACSF. Plasma (b) nicotine and (c) cotinine levels were not different between ACSF- $(n=1 \mathrm{I})$ and C8X $(n=12)$-treated animals following a bolus IV injection of nicotine $(200 \mu \mathrm{g} / \mathrm{kg})$ at the end of NSA. Data shown as mean+SEM.

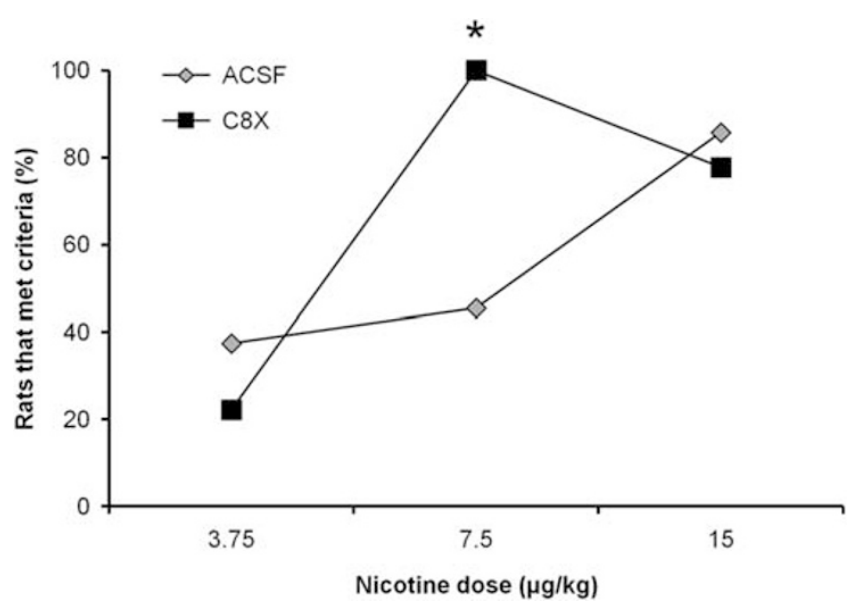

Figure 4 ICV injection of C8X results in a leftward shift of the acquisition dose response for nicotine, but does not alter NSA after behavior is acquired. In rats that self-administered $3.75 \mu \mathrm{g} / \mathrm{kg}, 3$ out of 8 acquired with ACSF vs 2 out of 9 acquired with C8X; for the $7.5 \mu \mathrm{g} / \mathrm{kg}$ dose, 10 out of 22 acquired with ACSF vs 21 out of 21 acquired with C $8 X$; and for the $15 \mu \mathrm{g} / \mathrm{kg}$ dose, 6 out of 7 acquired with ACSF vs 7 out of 9 with C8X. Data for $7.5 \mu \mathrm{g} / \mathrm{kg}$ dose was combined from two animal cohorts that produced the same results. In the first cohort, 4 out of 10 animals acquired with ACSF vs II out of II acquired with C8X and in the second cohort, 6 out of 12 animals acquired ACSF vs 10 out of 10 acquired with C8X. C8X was significantly higher when data was analyzed separately $(p<0.05$ for each cohort) or together. ${ }^{*} p<0.001$, C8X vs ACSF.

$p<0.001)$ and $\operatorname{ACSF}(\mathrm{F}(2.735,51.985)=15.669, p<0.001)$, where the rats reinstated their nicotine-seeking behavior after injection of the 60 (C8X, $p<0.001$; ACSF, $p=0.003$ ) and $150 \mu \mathrm{g} / \mathrm{kg}$ (C8X, $p<0.001$; ACSF, $p<0.001$ ) doses, but active lever presses were not different between ICV treatments (Figure 5c).

Plasma nicotine and cotinine levels were not different between ICV treatments after four $7.5 \mu \mathrm{g} / \mathrm{kg}$ infusions of nicotine, tested at the end of NSA (Figure $5 \mathrm{~d}$ and e). These results confirm that repeated administration of the inhibitor ICV did not alter peripheral metabolism of nicotine.

\section{DISCUSSION}

This present work demonstrates that (1) a dose-related increase in nicotine brain levels can be measured by microdialysis after IV nicotine administration, (2) within this dose range, the CYP2B inhibitor C8X given ICV increased nicotine brain levels without altering peripheral levels of nicotine, and (3) C8X given ICV increased acquisition and motivation during NSA. The increases in nicotine concentration measured after C8X treatment provides the first evidence to support the idea that altering brain CYP2B activity can influence nicotine levels in the brain. As nicotine brain levels increase with increasing systemic dose, it suggests that the higher brain nicotine levels after CYP2B inhibition are akin to being given a higher dose of nicotine. Human brain CYP2B levels are highly variable (Miksys et al, 2003) suggesting that individuals who are CYP2B6 slow metabolizers, or who are taking clinically used drugs that can inhibit this enzyme, such as the antiplatelet agent clopidogrel, the antifungal clomitrozole, and the antidepressant sertraline (Richter et al, 2004; Walsky et al, 2006), could have reduced metabolism of nicotine in the brain.

Injecting the CYP2B inhibitor directly in the brain modified the reinforcing effects of nicotine. C8X-treated rats were willing to press more on the active lever to receive one nicotine infusion during $\mathrm{PR}$, and $\mathrm{C} 8 \mathrm{X}$ treatment also increased acquisition of NSA, suggesting a leftward shift in the dose-acquisition curve for nicotine. This increase in motivation and in acquisition suggests that inhibiting brain CYP2B activity can increase the reinforcing effect of nicotine in NSA, possibly by increasing the nicotine levels in the brain. The effect of CYP2B inhibition on acquisition of NSA was found at a low infusion dose of $7.5 \mu \mathrm{g}$ where $100 \%$ of the rats treated with C8X acquired NSA, but only 50\% of those treated with ASCF acquired NSA. This effect was observed in two separate experiments. Higher nicotine doses result in greater dopamine release in the nucleus accumbens (Di Chiara and Imperato, 1988; Marshall et al, 1997), which is a characteristic response to systemic administration of drugs of abuse (Di Chiara and Imperato, 1988), and is considered 

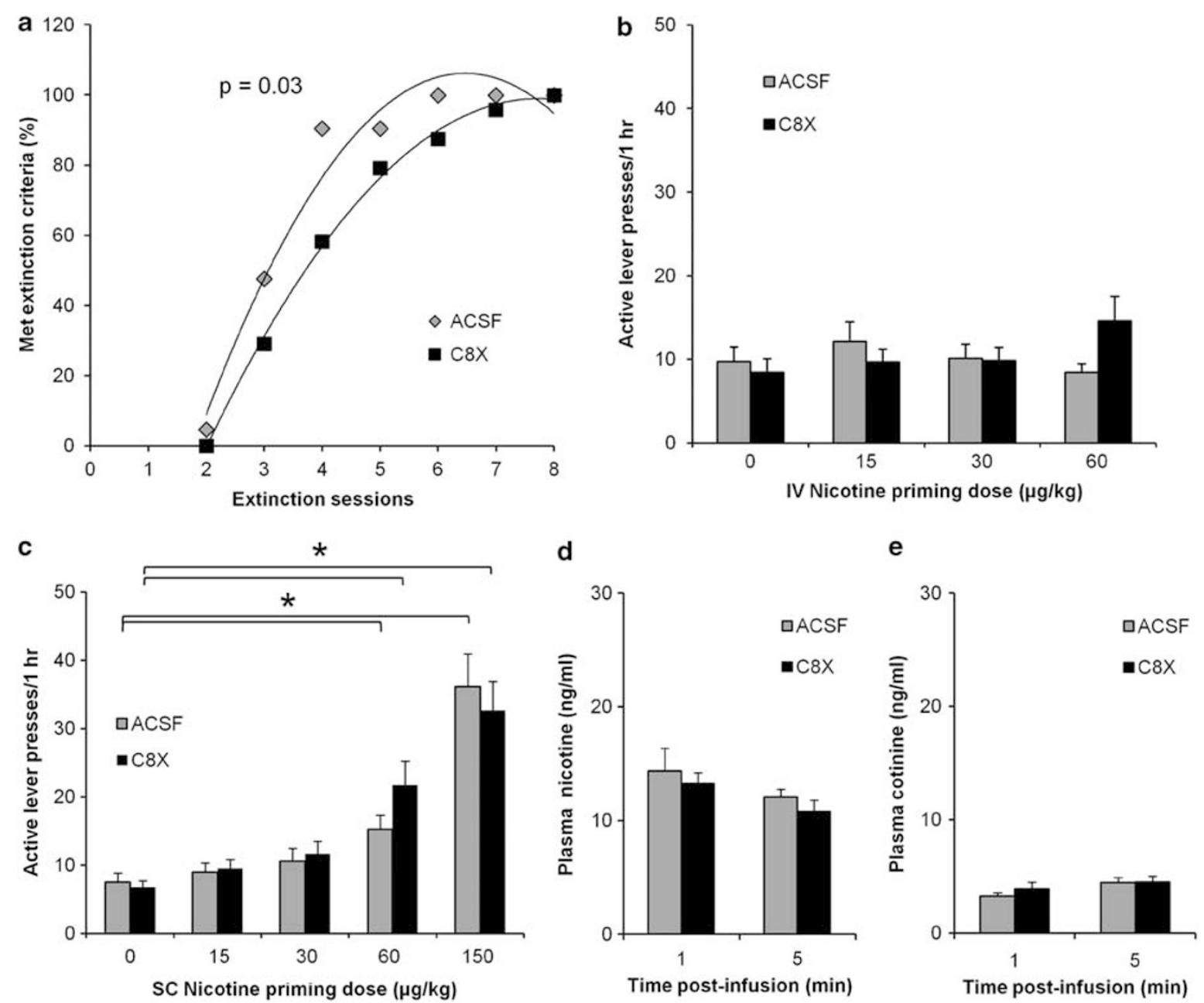

Figure 5 ICV injection of C8X can increase motivation to obtain nicotine in nicotine-seeking behavior, and repeated ICV injections of C8X does not alter peripheral nicotine metabolism. (a) Mean active lever presses ( \pm SEM) for the first four daily extinction sessions (C8X: $40 \pm 6,28 \pm 4,21 \pm 2$, and 23 \pm 3 ; ACSF: $39 \pm 4,26 \pm 4,26 \pm 3$, and $25 \pm 2)$ were not different between C8X $(n=24)$ and ACSF $(n=21)$ groups (Supplementary Figure). Animals then underwent multiple extinction sessions the same day until they reached extinction criteria. Data shown is the proportion of C8X and ACSF rats that met extinction criteria over these extinction sessions where C8X-treated animals needed more sessions to meet criteria. During nicotine reinstatement testing, mean active lever presses between C8X and ACSF were not different after (b) IV (C8X: $n=17$, ACSF: $n=18$ ) or (c) SC (C8X: $n=24, A C S F: n=21)$ nicotine priming injections at all doses tested. Mean active lever presses between C $8 X$ and ACSF after $60 \mu \mathrm{g} / \mathrm{kg} / \mathrm{IV}$ approached significance $(p=0.06)$. $* 2<0.05$, saline $(0 \mu \mathrm{g} / \mathrm{kg}$ nicotine) vs 60 and $150 \mu \mathrm{g} / \mathrm{kg} / \mathrm{SC}$ for both C8X and ACSF. There was no difference in plasma (d) nicotine and (e) cotinine between ACSF and C8X treatments after four nicotine infusions were given in the operant SA chamber ( $7.5 \mu \mathrm{g} / \mathrm{kg} /$ infusion) at the end of NSA in a subset of rats ( $n=8$ for both $C 8 X$ and ACSF). Data shown as mean \pm SEM.

as one mechanism of creating a drug-reward association that leads to addiction. CYP2B is expressed in multiple brain regions (Miksys et al, 2003) including the nucleus accumbens, and also in other regions associated with nicotine addiction, such as the frontal cortex (Markou, 2008) and cingulate gyrus (McClernon et al, 2007). As our C8X injections were given ICV to globally inhibit CYP2B, it is possible that inhibition in any of these regions or nearby regions that express CYP2B contributed to the microdialysis and behavioral findings. Pilot data in humans suggest that CYP2B6 slow metabolizers show a faster conversion to dependence in adolescence (Hoffmann et al, 2006), which is consistent with potentially higher brain nicotine levels during initial stages of smoking. Higher brain nicotine levels when smoking behavior is first established could result in a greater reinforcing effect of nicotine.
C8X-treated animals also needed more sessions to meet extinction criteria, demonstrating that the animals were more persistent in responding to the active lever. However, there was no effect of $\mathrm{C} 8 \mathrm{X}$ on nicotine reinstatement; priming with IV in doses ranging from 15 to $60 \mu \mathrm{g} / \mathrm{kg}$ did not reinstate nicotine seeking in either treatment groups albeit at the $60 \mu \mathrm{g} / \mathrm{kg}$ dose, a trend toward reinstatement of nicotine seeking was observed in the C8X group $(p=0.06)$. It is possible that the training dose $(7.5 \mu \mathrm{g} / \mathrm{kg})$ was not sufficient to elicit a significant effect of C8X on reinstatement. This is, however, quite unlikely as significant reinstatement of nicotine seeking was observed with SC priming of $0.15 \mathrm{mg} / \mathrm{kg}$ of nicotine in both experimental groups. It should be noted that priming with nicotine through the IV route can produce a relatively modest reinstatement of nicotine seeking relative to that induced by SC priming (Chiamulera et al, 1996; 
Shaham et al, 1997). CYP2B6 slow metabolizers report greater craving scores during abstinence and are more likely to relapse (Lee et al, 2007a; Lerman et al, 2007), therefore it is possible that higher brain nicotine levels during smoking resulted in greater reinforcement that may result in greater behavioral response to nicotine withdrawal during abstinence in these individuals.

It is possible that the effects of C8X on NSA could be unrelated to CYP2B-mediated nicotine metabolism. However, brain, but not plasma, nicotine levels were elevated during this treatment. In addition, greater acquisition was not seen at higher and lower nicotine doses, suggesting that C8X did not increase acquisition of NSA behavior in general, but instead resulted in a leftward shift in nicotine's doseresponse curve. Also, active and inactive lever presses were not different after acquisition, suggesting that C8X itself did not increase responding for both levers once rats established NSA. Another possibility is that C8X increased responding for the cues; however, more extinction sessions were required to extinguish NSA behavior without the presence of cues, suggesting that C8X-treated animals still persisted in pressing on the active lever even without cues. Also, it is possible that C8X's effects on brain nicotine levels and NSA behavior could be indirect; however, although other alkyl xanthate compounds have antitumor and antiviral properties (Sauer et al, 1984; Schick et al, 1989), there are no known biological effects of C8X other than its ability to inhibit CYP2B (Yanev et al, 1999, 2000). As C8X has been previously established as a specific CYP2B inhibitor (Khokhar and Tyndale, 2011, 2012, 2014; Miksys and Tyndale, 2009; Yanev et al, 2000), these observations, along with the increase in nicotine levels measured via microdialysis after C8X treatment, support the idea that C8X's effects are due to CYP2B inhibition and reduced nicotine metabolism.

Our findings demonstrate that brain CYP2B can influence nicotine levels independent of liver CYP2B and that reducing brain CYP2B activity can increase brain nicotine levels and resulting nicotine-mediated behaviors. The effect of reducing brain CYP2B activity in this rat model is consistent with observed smoking-related behaviors in human CYP2B6 slow metabolizers, which supports the idea that reduced brain CYP2B6 activity might influence smoking behaviors. Together with data using other CYP2B substrates (Khokhar and Tyndale, 2011, 2012, 2014,), this data suggest that brain CYP2B can influence the drug levels in the brain and their subsequent behavioral effects. These findings also indicate clinical implications for individuals with CYP2B6 genetic variation and those prescribed CYP2B6 inhibitors or inducers, because variation in brain-specific enzyme activity may alter drug response. As many CNS-acting, clinical drugs are substrates and/or inhibitors for CYP2B, brain-specific activity of CYP2B could be another source of variation in the inter-individual response to these drugs.

\section{FUNDING AND DISCLOSURE}

This work was funded by NIDA R21 DA029160-01, CIHR MOP97751, Centre for Addiction and Mental Health (CAMH), Campbell Family Mental Health Research Institute of CAMH, the CAMH foundation, an Endowed Chair in Addictions ( $\mathrm{RF}$ Tyndale), the Canada Foundation for
Innovation (\#20289 and \#16014), and the Ontario Ministry of Research and Innovation. The remaining authors declare no conflict of interest.

\section{ACKNOWLEDGMENTS}

We thank Fariba Baghai Wadji, Dr Bin Zhao, Maria Novalen, and Zhauxia Li for their technical assistance.

\section{REFERENCES}

Anandatheerthavarada HK, Boyd MR, Ravindranath V (1992). Characterization of a phenobarbital-inducible cytochrome P-450, NADPH-cytochrome P-450 reductase and reconstituted cytochrome P-450 mono-oxygenase system from rat brain. Evidence for constitutive presence in rat and human brain. Biochem J 288: 483-488.

Chiamulera C, Borgo C, Falchetto S, Valerio E, Tessari M (1996). Nicotine reinstatement of nicotine self-administration after longterm extinction. Psychopharmacology (Berl) 127: 102-107.

Corrigall WA, Coen KM (1989). Nicotine maintains robust selfadministration in rats on a limited-access schedule. Psychopharmacology (Berl) 99: 473-478.

Craig EL, Zhao B, Cui JZ, Novalen M, Miksys S, Tyndale RF (2014). Nicotine pharmacokinetics in rats is altered as a function of age, impacting the interpretation of animal model data. Drug Metab Dispos 42: 1447-1455.

Crettol S, Deglon JJ, Besson J, Croquette-Krokkar M, Gothuey I, Hammig $\mathrm{R}$ et al (2005). Methadone enantiomer plasma levels, CYP2B6, CYP2C19, and CYP2C9 genotypes, and response to treatment. Clin Pharmacol Ther 78: 593-604.

Di Chiara G, Imperato A (1988). Drugs abused by humans preferentially increase synaptic dopamine concentrations in the mesolimbic system of freely moving rats. Proc Natl Acad Sci USA 85: 5274-5278.

Dobrinas M, Crettol S, Oneda B, Lahyani R, Rotger M, Choong E et al (2013). Contribution of CYP2B6 alleles in explaining extreme (S)-methadone plasma levels: a CYP2B6 gene resequencing study. Pharmacogenet Genomics 23: 84-93.

Donny EC, Caggiula AR, Mielke MM, Booth S, Gharib MA, Hoffman A et al (1999). Nicotine self-administration in rats on a progressive ratio schedule of reinforcement. Psychopharmacology (Berl) 147: 135-142.

Ekins S, Iyer M, Krasowski MD, Kharasch ED (2008). Molecular characterization of CYP2B6 substrates. Curr Drug Metab 9: 363-373.

Ferguson CS, Tyndale RF (2011). Cytochromes P450 enzymes in the brain: emerging evidence for biological significance. Trends Pharmacol Sci 32: 708-714.

Garcia KL, Le AD, Tyndale RF (2014). Effect of food training and training dose on nicotine self-administration in rats. Behav Brain Res 274: 10-18.

Gerber JG, Rhodes RJ, Gal J (2004). Stereoselective metabolism of methadone N-demethylation by cytochrome P4502B6 and 2C19. Chirality 16: 36-44.

Gervot L, Rochat B, Gautier JC, Bohnenstengel F, Kroemer H, de Berardinis V et al (1999). Human CYP2B6: expression, inducibility and catalytic activities. Pharmacogenetics 9: 295-306.

Hammond DK, Bjercke RJ, Langone JJ, Strobel HW (1991). Metabolism of nicotine by rat liver cytochromes P-450. Assessment utilizing monoclonal antibodies to nicotine and cotinine. Drug Metab Dispos 19: 804-808.

Hesse LM, Venkatakrishnan $\mathrm{K}$, Court MH, von Moltke LL, Duan SX, Shader RI et al (2000). CYP2B6 mediates the in vitro hydroxylation of bupropion: potential drug interactions with other antidepressants. Drug Metab Dispos 28: 1176-1183. 
Hoffmann E, O'Loughlin J, Karp I, Tyndale RF (2006). CYP2B6 and CYP2A6 Genotype: Impact on Acquisition of ICD10 Tobacco Dependence in Caucasian Adolescents. Society for Research on Nicotine and Tobacco: Orlando, FL, USA.

Jacob P 3rd, Ulgen M, Gorrod JW (1997). Metabolism of (-)-(S)nicotine by guinea pig and rat brain: identification of cotinine. Eur J Drug Metab Pharmacokinet 22: 391-394.

Khokhar JY, Tyndale RF (2011). Drug metabolism within the brain changes drug response: selective manipulation of brain CYP2B alters propofol effects. Neuropsychopharmacology 36: 692-700.

Khokhar JY, Tyndale RF (2012). Rat brain CYP2B-enzymatic activation of chlorpyrifos to the oxon mediates cholinergic neurotoxicity. Toxicol Sci 126: 325-335.

Khokhar JY, Tyndale RF (2014). Intracerebroventricularly and systemically delivered inhibitor of brain CYP2B (C8-Xanthate), even following chlorpyrifos exposure, reduces chlorpyrifos activation and toxicity in male rats. Toxicol Sci 140: 49-60.

Kirchheiner J, Klein C, Meineke I, Sasse J, Zanger UM, Murdter TE et al (2003). Bupropion and 4-OH-bupropion pharmacokinetics in relation to genetic polymorphisms in CYP2B6. Pharmacogenetics 13: 619-626.

Lang T, Klein K, Fischer J, Nussler AK, Neuhaus P, Hofmann U et al (2001). Extensive genetic polymorphism in the human CYP2B6 gene with impact on expression and function in human liver. Pharmacogenetics 11: 399-415.

Lee AM, Jepson C, Hoffmann E, Epstein L, Hawk LW, Lerman C et al (2007a). CYP2B6 genotype alters abstinence rates in a bupropion smoking cessation trial. Biol Psychiatry 62: 635-641.

Lee AM, Jepson C, Shields PG, Benowitz N, Lerman C, Tyndale RF (2007b). CYP2B6 genotype does not alter nicotine metabolism, plasma levels, or abstinence with nicotine replacement therapy. Cancer Epidemiol Biomarkers Prev 16: 1312-1314.

Lee AM, Miksys S, Palmour R, Tyndale RF (2006). CYP2B6 is expressed in African Green monkey brain and is induced by chronic nicotine treatment. Neuropharmacology 50: 441-450.

Lerman C, LeSage MG, Perkins KA, O'Malley SS, Siegel SJ, Benowitz NL et al (2007). Translational research in medication development for nicotine dependence. Nature Rev Drug Discov 6: 746-762.

Markou A (2008). Review. Neurobiology of nicotine dependence. Philos Trans R Soc Lond B Biol Sci 363: 3159-3168.

Marshall DL, Redfern PH, Wonnacott S (1997). Presynaptic nicotinic modulation of dopamine release in the three ascending pathways studied by in vivo microdialysis: comparison of naive and chronic nicotine-treated rats. J Neurochem 68: 1511-1519.

McClernon FJ, Kozink RV, Rose JE (2007). Individual differences in nicotine dependence, withdrawal symptoms, and sex predict transient fMRI-BOLD responses to smoking cues. Neuropsychopharmacology 33: 2148-2157.

Miksys S, Hoffmann E, Tyndale RF (2000). Regional and cellular induction of nicotine-metabolizing CYP2B1 in rat brain by chronic nicotine treatment. Biochem Pharmacol 59: 1501-1511.

Miksys S, Lerman C, Shields PG, Mash DC, Tyndale RF (2003). Smoking, alcoholism and genetic polymorphisms alter CYP2B6 levels in human brain. Neuropharmacology 45.

Miksys S, Tyndale RF (2009). Brain drug-metabolizing cytochrome P450 enzymes are active in vivo, demonstrated by mechanismbased enzyme inhibition. Neuropsychopharmacology 34: 634-640.

Paxinos G, Watson C (1986). The Rat Brain in Stereotaxic Coordinates. 2nd edn. Academic Press: San Diego, CA, USA.
Rapier C, Lunt GG, Wonnacott S (1988). Stereoselective nicotineinduced release of dopamine from striatal synaptosomes: concentration dependence and repetitive stimulation. J Neurochem 50: 1123-1130.

Richter T, Murdter TE, Heinkele G, Pleiss J, Tatzel S, Schwab M et al (2004). Potent mechanism-based inhibition of human CYP2B6 by clopidogrel and ticlopidine. J Pharmacol Exp Ther 308: 189-197.

Sauer G, Amtmann E, Melber K, Knapp A, Muller K, Hummel K et al (1984). DNA and RNA virus species are inhibited by xanthates, a class of antiviral compounds with unique properties. Proc Natl Acad Sci USA 81: 3263-3267.

Schick HD, Amtmann E, Berdel WE, Danhauser-Riedl S, Reichert A, Steinhauser G et al (1989). Antitumoral activity of a xanthate compound. I. Cytotoxicity studies with neoplastic cell lines in vitro. Cancer Lett 46: 143-147.

Schilter B, Omiecinski CJ (1993). Regional distribution and expression modulation of cytochrome P-450 and epoxide hydrolase mRNAs in the rat brain. Mol Pharmacol 44: 990-996.

Shaham Y, Adamson LK, Grocki S, Corrigall WA (1997). Reinstatement and spontaneous recovery of nicotine seeking in rats. Psychopharmacology (Berl) 130: 396-403.

Shram MJ, Li Z, Le AD (2008). Age differences in the spontaneous acquisition of nicotine self-administration in male Wistar and Long-Evans rats. Psychopharmacology (Berl) 197: 45-58.

Siu EC, Wildenauer DB, Tyndale RF (2006). Nicotine selfadministration in mice is associated with rates of nicotine inactivation by CYP2A5. Psychopharmacology (Berl) 184: 401-408.

Tsuchiya K, Gatanaga H, Tachikawa N, Teruya K, Kikuchi Y, Yoshino $\mathrm{M}$ et al (2004). Homozygous CYP2B6 ${ }^{*} 6(\mathrm{Q} 172 \mathrm{H}$ and K262R) correlates with high plasma efavirenz concentrations in HIV-1 patients treated with standard efavirenz-containing regimens. Biochem Biophys Res Commun 319: 1322-1326.

Vieira-Brock PL, Miller EI, Nielsen SM, Fleckenstein AE, Wilkins DG (2011). Simultaneous quantification of nicotine and metabolites in rat brain by liquid chromatography-tandem mass spectrometry. J Chromatogr B 879(30): 3465-3474.

Walsky RL, Astuccio AV, Obach RS (2006). Evaluation of 227 drugs for in vitro inhibition of cytochrome P450 2B6. J Clin Pharmacol 46: 1426-1438.

Yamanaka H, Nakajima M, Fukami T, Sakai H, Nakamura A, Katoh $\mathrm{M}$ et al (2005). CYP2A6 AND CYP2B6 are involved in nornicotine formation from nicotine in humans: interindividual differences in these contributions. Drug Metab Dispos 33: $1811-1818$

Yamazaki H, Inoue K, Hashimoto M, Shimada T (1999). Roles of CYP2A6 and CYP2B6 in nicotine C-oxidation by human liver microsomes. Arch Toxicol 73: 65-70.

Yanev S, Kent UM, Pandova B, Hollenberg PF (1999). Selective mechanism-based inactivation of cytochromes P-450 2B1 and P-450 2B6 by a series of xanthates. Drug Metab Dispos 27: 600-604.

Yanev SG, Kent UM, Roberts ES, Ballou DP, Hollenberg PF (2000). Mechanistic studies of cytochrome P450 2B1 inactivation by xanthates. Arch Biochem Biophys 378: 157-166.

Zanger UM, Klein K, Saussele T, Blievernicht J, Hofmann MH, Schwab M (2007). Polymorphic CYP2B6: molecular mechanisms and emerging clinical significance. Pharmacogenomics 8: 743-759.

Supplementary Information accompanies the paper on the Neuropsychopharmacology website (http://www.nature.com/npp) 